\title{
Self-Division Behavier of TiB Particles in TiB/Ti Composite
}

\author{
Tatsuaki Yoshihiro*, Toshihiro Tsuchiyama and Setsuo Takaki \\ Department of Material Science and Engineering, Kyushu University, Fukuoka 812-8581, Japan
}

The change in dispersion of $\mathrm{TiB}$ boride formed through the chemical reaction, $\mathrm{Ti}+\mathrm{CrB} \rightarrow \mathrm{Cr}+\mathrm{TiB}$, was investigated in the $\mathrm{Ti}-\mathrm{Cr}$ system powder compact containing CrB boride particles. EPMA analysis revealed that the shape of the TiB particles was granular type at first, but they began to divide into a large number of fine plate-like TiB particles at the sintering temperature (self-division phenomenon). Although this seems to be contrary to the Ostwald ripening mechanism, the phenomenon could be reasonably explained in terms of total interfacial energy in the system: Considering the grain boundary energy within the granular TiB and the low interfacial energy of coherent plate-like TiB/matrix interface, the total interfacial energy was found to be decreased through the self-division. It was concluded that the difference in the total interfacial energy works as driving force for the self-division phenomenon.

(Received December 10, 2003; Accepted March 12, 2004)

Keywords: TiB boride, titanium composite, reaction sintering, interfacial energy, self-division, driving force

\section{Introduction}

Titanium (Ti) alloys have higher specific strength and corrosion resistance than those of steel. However, the applications of Ti alloys to structural materials are limited to special uses so far, because they have problems of poor heat and wear resistance as well as their high manufacturing cost. In order to solve these problems and to apply Ti alloys widely to general structural materials, the powder metallurgy technology, which enables the near-net-shape manufacturing, recently attracts great attention. In particular, the TiB dispersed $\mathrm{Ti}$ composites ( $\mathrm{TiB} / \mathrm{Ti}$ composites) manufactured by the blended elemental method ${ }^{1)}$ can markedly raise hardness and heat resistance of $\mathrm{Ti}$ owing to the hard and thermally stable TiB particles without reducing fatigue strength and toughness too much. From these reasons, the $\mathrm{TiB} / \mathrm{Ti}$ composites are expected as a wear-resistant or heatresistant $\mathrm{Ti}$ alloy for the next generation. ${ }^{2)}$

In the case of the $\mathrm{TiB} / \mathrm{Ti}$ composites, the boride of $\mathrm{TiB}$ can not be directly blended with the ingredient powder since TiB is unstable material in itself. In general, other stable boride powders such as $\mathrm{CrB}, \mathrm{MoB}$ and $\mathrm{FeB}$ are added to the base $\mathrm{Ti}$ alloy powder, and then the chemical reaction of $\mathrm{Ti}+$ $\mathrm{MB} \rightarrow \mathrm{M}+\mathrm{TiB}$ ( $\mathrm{M}$ : metal atoms, such as $\mathrm{Cr}, \mathrm{Mo}$, and $\mathrm{Fe}$ ) is used for dispersing TiB particles in the Ti based alloy. This process is called as 'reaction sintering'. ${ }^{3)}$ However, in the research field on the $\mathrm{TiB} / \mathrm{Ti}$ composites produced by the reaction sintering, most of the physical or chemical phenomena caused during reaction sintering have not been sufficiently cleared although there are many investigations on the manufacturing methods or mechanical properties of produced materials. ${ }^{3-6)}$

We investigated the reaction process at sintering temperature in a green compact containing $\mathrm{CrB}$ particles, ${ }^{7)}$ and found that the reaction begins from the $\mathrm{CrB}$ particle surface and proceeds toward inside of the particle topochemically. Furthermore, as a result of analysis of the reaction rate using the unreacted core model, the relationship between the diameter of a blended $\mathrm{CrB}$ powder and the reaction finish

*Present address: Hitachi Powder Metals Co., Ltd, 270-2295, Japan time was formulated theoretically. On the other hand, according to the report by Saito et al., ${ }^{2)}$ the TiB particles change its shape from original granular type to plate-like type after finishing the reaction. Since the morphology and dispersion of $\mathrm{TiB}$ particles give a great influence on the mechanical properties, it is important to clear the mechanism of the change in shape of TiB particles and to establish the technology for controlling the dispersion of $\mathrm{TiB}$ particles.

In this study, the change in dispersion of TiB particles after finishing the reaction was investigated in a $\mathrm{Ti}-\mathrm{Cr}$ based sintering alloy, and then the mechanism of 'self-division' of TiB particle was proposed on the basis of the change in total interfacial energy.

\section{Experimental Procedures}

$\mathrm{HDH} \mathrm{Ti}$ powder and $\mathrm{CrB}$ boride powder were used as ingredient powders in this study. Table 1 and Fig. 1 show chemical compositions and SEM images of the powders, respectively. Both powders have a size of $45 \mu \mathrm{m}$ $(-325$ mesh). These powders were blended so that the composition after the reaction sintering becomes 4 vol\% TiB/ Ti-4 mass $\% \mathrm{Cr}$ matrix, and then formed into green compact by cold isostatic press (CIP) with a pressure of $196 \mathrm{MPa}$. The reason why the matrix composition was adjusted to $4 \% \mathrm{Cr}$ is that $\mathrm{Ti}-4 \% \mathrm{Cr}$ alloy has excellent mechanical properties ${ }^{8)}$ as well as formability at high temperature through superplastic deformation. ${ }^{9)}$ The $4 \% \mathrm{Cr}$ alloyed to the matrix is supplied from $\mathrm{CrB}$ powder on the reaction sintering. The green compact obtained by CIP was heated at a rate of 0.17 to $1473 \mathrm{~K}$ in a vacuum and then held at this temperature for 3.6$108 \mathrm{ks}$, followed by slow cooling at a rate of $0.17 \mathrm{~K} / \mathrm{s}$. Chemical composition of sintered materials were measured by means of Electron Probe X-ray Microanalyzer (EPMA).

Table 1 Chemical compositions of $\mathrm{Ti}$ and $\mathrm{CrB}$ powders used. (mass\%).

\begin{tabular}{cccccccc}
\hline Ti & $\begin{array}{c}\mathrm{Fe} \\
0.016\end{array}$ & $\begin{array}{c}\mathrm{Cl} \\
<0.01\end{array}$ & $\begin{array}{c}\mathrm{O} \\
0.27\end{array}$ & $\begin{array}{c}\mathrm{N} \\
0.025\end{array}$ & $\begin{array}{c}\mathrm{C} \\
0.007\end{array}$ & $\begin{array}{c}\mathrm{H} \\
0.017\end{array}$ & $\begin{array}{c}\mathrm{Ti} \\
\text { bal. }\end{array}$ \\
\hline \multirow{2}{*}{$\mathrm{CrB}$} & $\mathrm{Fe}$ & $\mathrm{Si}$ & $\mathrm{Mg}$ & $\mathrm{O}$ & $\mathrm{N}$ & $\mathrm{B}$ & $\mathrm{Cr}$ \\
& 0.066 & 0.006 & 0.017 & 0.32 & 0.008 & 17.3 & bal. \\
\hline
\end{tabular}



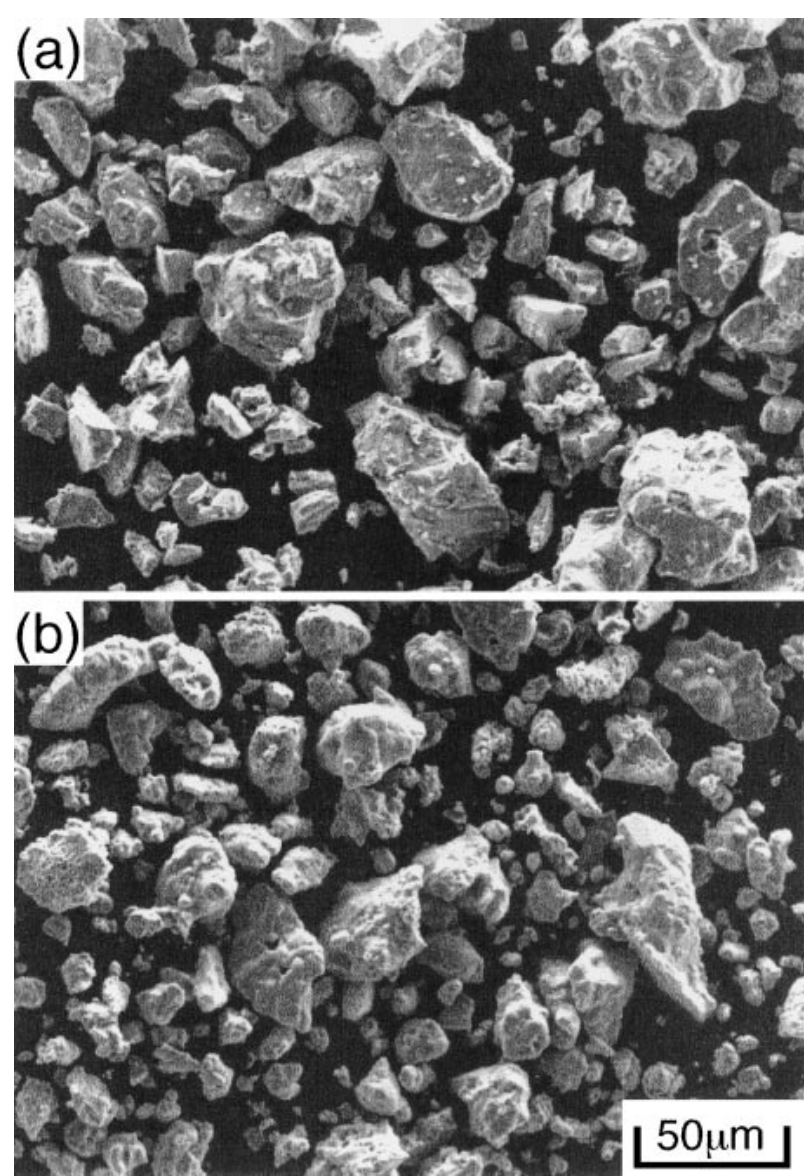

Fig. 1 Scanning electron micrographs showing the shape of $\mathrm{Ti}$ (a) and $\mathrm{CrB}$ (b) powders used.

\section{Results and Discussion}

\subsection{Microstructural change during sintering}

The chemical reaction occurred during sintering and the Gibbs free energy ${ }^{10)}$ change on the reaction, $\Delta G_{0}$, are expressed by eq. (1) and eq. (2), respectively.

$$
\begin{aligned}
& \mathrm{Ti}+\mathrm{CrB} \rightarrow \mathrm{TiB}+\mathrm{Cr} \\
& \Delta G_{0}=0.0130 T-87.8(\mathrm{~kJ} / \mathrm{mol})
\end{aligned}
$$

where, $T$ is the absolute temperature $(\mathrm{K})$. The reaction proceeds in the whole temperature range dealt in this research (room temperature to $1573 \mathrm{~K}$ ) because the condition of $\Delta G_{0}<0$ always holds. Figure 2 represents X-ray diffraction patterns showing the reaction on heating up to $1573 \mathrm{~K}$ at a rate of $0.17 \mathrm{~K} / \mathrm{s}$. The specimens were water-cooled from selected temperature on heating. When the temperature reaches $1273 \mathrm{~K}$, the formation of TiB starts, and peaks of bcc phase also appear in the diffraction pattern. The detected bcc phase is retained $\beta$ which was stable at the heated temperature and did not undergo the phase transformation to $\alpha$ on cooling. The reaction almost finishes at $1473 \mathrm{~K}$ although some boride particles with an unreacted $\mathrm{CrB}$ core were found. ${ }^{7)}$ From the industrial point of view, the reaction should be completed in a short time, and besides, the density of Ti$\mathrm{Cr}$ matrix must be increased as low as possible to keep sufficient ductility of the material. Thus, the sintering temperature was set at a rather high temperature of

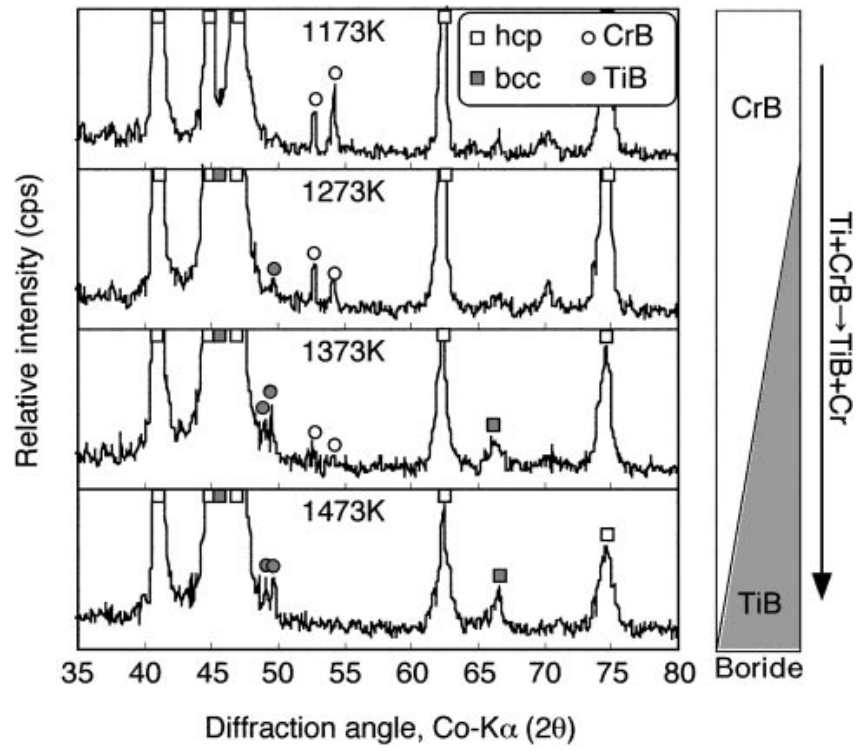

Fig. 2 X-ray diffraction patterns of specimens heated to various temperatures $(1173 \sim 1573 \mathrm{~K})$ at $0.17 \mathrm{~K} / \mathrm{s}$ and then water-quenched.

$1473 \mathrm{~K}^{11)}$ in the following investigations.

Figure 3 shows the dispersion and the chemical composition of TiB in the specimen which was sintered at $1473 \mathrm{~K}$ for $1.2 \mathrm{ks}$. The dispersion and shape of the TiB particles have hardly changed from those of original $\mathrm{CrB}$ powders blended in the green compact, because the reaction from $\mathrm{CrB}$ to $\mathrm{TiB}$ occurs in-situ during sintering and proceeds topochemically from the particle surface toward inner side as reported in the previous paper. ${ }^{7)}$ In the characteristic X-ray images, it is confirmed that $\mathrm{Ti}$ and $\mathrm{B}$ are condensed but $\mathrm{Cr}$ is diluted in the boride. It should be noted here that tiny plate-like precipitates are scattered within the matrix. The precipitates can be also defined as TiB boride because they have the same chemical composition as that of the granular TiB particle. To clarify the formation process of the plate-like $\mathrm{TiB}$, the change in dispersion of $\mathrm{TiB}$ during the sintering at $1473 \mathrm{~K}$ was observed with back scattered electron images of EPMA (Fig. 4). The coarse granular TiB particles, which were observed in the early stage of sintering, gradually disappear and the number of plate-like TiB particles is increased. After sintering more than $97.2 \mathrm{ks}$, the granular TiB can be hardly observed. Since some groups of fine plate-like TiB particles are formed where the granular TiB have originally existed as shown by the arrows, the plate-like TiB seems to have been formed through the division of coarse granular TiB. In the 291.6 ks sintered material, uniformly dispersed fine plate-like $\mathrm{TiB}$ particles are observed. Figure 5 shows the change in morphology of a TiB particle during sintering at $1473 \mathrm{~K}$. The initial granular TiB in the $1.2 \mathrm{ks}$ sintered material has smooth $\mathrm{TiB} /$ matrix interface (a), but it becomes rougher with increasing sintering time (b). The division of TiB is clearly observed in the $97.2 \mathrm{ks}$ sintered material (c), and the divided TiB particles grow from the original position of the initial granular TiB toward $\beta$ matrix with forming plate-like precipitates. In the $291.6 \mathrm{ks}$ sintered material (d), the division has almost completed, but the plate-like TiB particles increase the thickness further more. The chemical composition of the $\mathrm{TiB}$ is not changed during the division as 


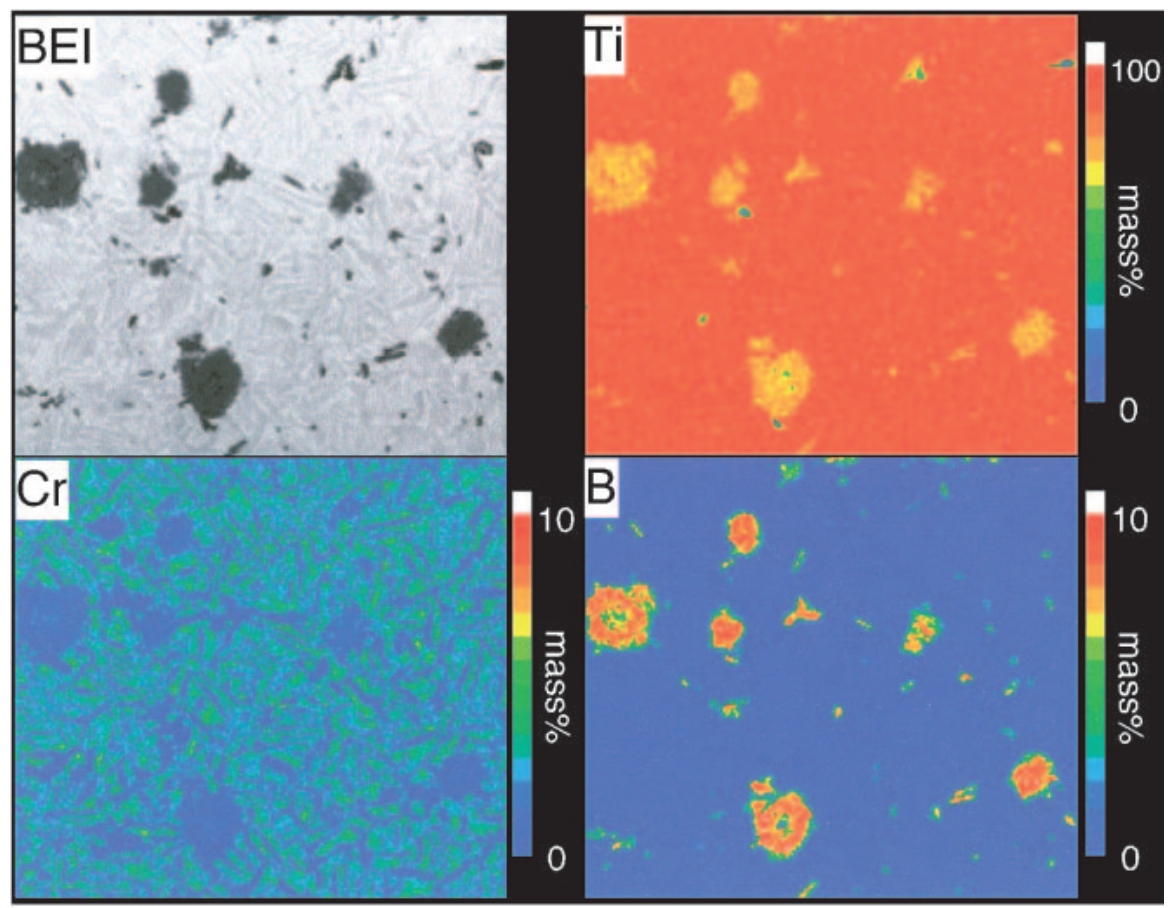

Fig. 3 EPMA images of a specimen sintered at $1473 \mathrm{~K}$ for $1.2 \mathrm{ks}$.

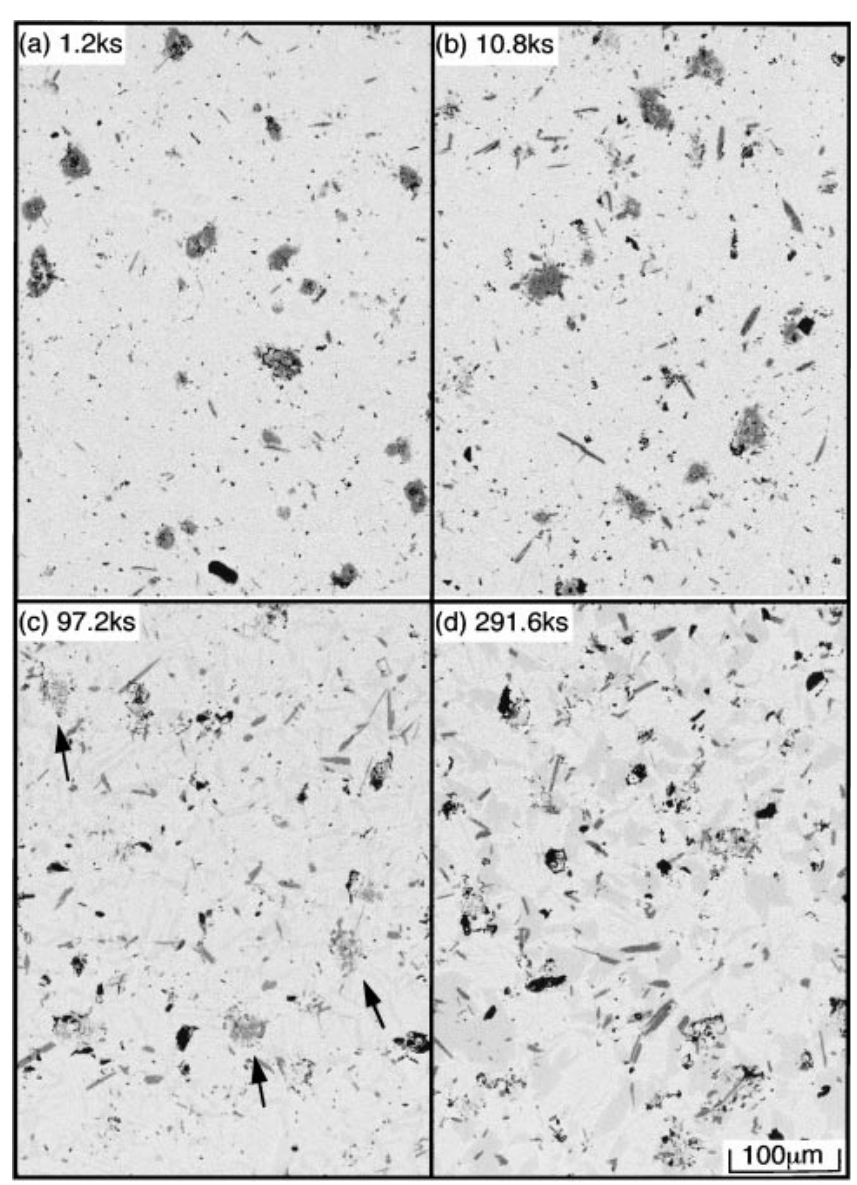

Fig. 4 Back scattered electron images showing microstructure after sintering at $1473 \mathrm{~K}$ for $1.2 \mathrm{ks}$ (a), $10.8 \mathrm{ks}$ (b), $97.2 \mathrm{ks}$ (c) and $291.6 \mathrm{ks}$ (d).

mentioned above. In this paper, we call such a change in morphology of TiB particle without the change of crystal structure as 'self-division'.

\subsection{Total interfacial energy change with self-division of TiB particle}

In general, the second phase particles dispersed in material grow at elevated temperature on the mechanism of Ostwald ripening, meaning that small particles dissolve into matrix and other larger particles grow without changing the volume fraction of the particle. The driving force for Ostwald ripening corresponds to the interfacial energy between the precipitate and matrix. Therefore, the total area of the interface decreases with Ostwald ripening. However, when a large TiB particle is divided into many fine TiB particles by the self-division, the total area of $\mathrm{TiB} /$ matrix interface is absolutely increased.

To understand the thermodynamic validity of the selfdivision phenomenon, we should consider the effect of the coherency on the interfacial energy and the contribution of grain boundary within the $\mathrm{TiB}$ particle. The $\mathrm{TiB} /$ matrix interface for the initial granular $\mathrm{TiB}$ can be regarded as an incoherent interface with high energy, because the granular TiB particles are formed by the transformation from the blended $\mathrm{CrB}$ particles which have no specific crystallographic orientation relationship with the matrix. On the other hand, it was reported that the TiB precipitated in $\beta$ type $\mathrm{Ti}$ alloy has a coherent interface with $\beta$ matrix ${ }^{2)}$ and grows in the $\langle 111\rangle$ directions of the $\beta .^{12)}$ It is generally known that interfacial energy of such a coherent interface is much lower than incoherent interfaces. Thus, the interfacial energy per unit area should be smaller in the plate-like TiB particles than that in the granular TiB particles. Figure 6 shows SEM images of the specimen sintered at $1473 \mathrm{~K}$ for $1.2 \mathrm{ks}$. In the magnified image of a granular TiB particle (b), it is found that grain boundaries exist within the particle, which means that the $\mathrm{TiB}$ is a fine-grained polycrystalline particle. The grain size is around $1 \mu \mathrm{m}$. On the other hand, there is no grain boundary within the plate-like $\mathrm{TiB}$ as found in the magnified 


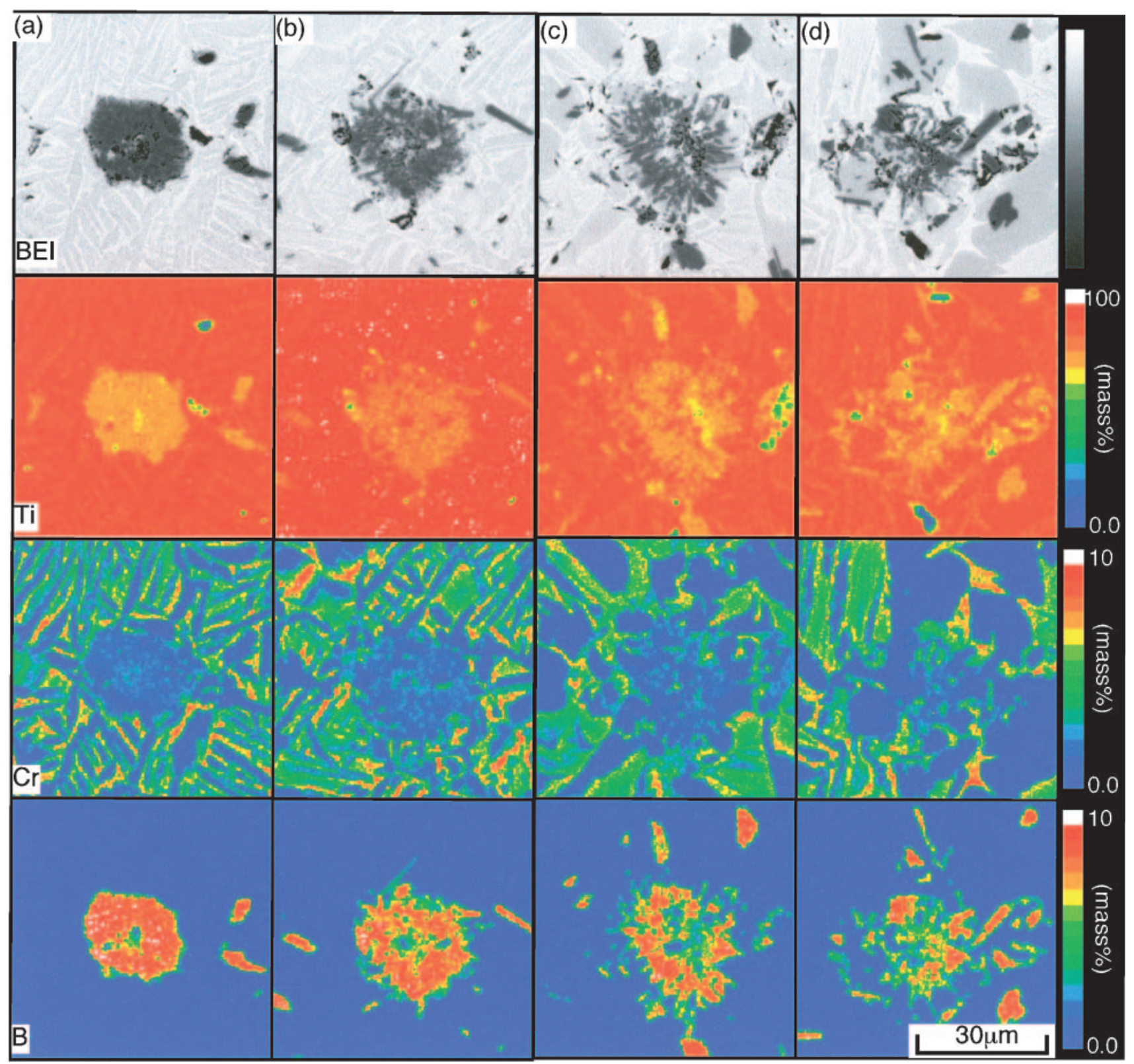

Fig. 5 Change in morphology of a TiB particle during sintering at $1473 \mathrm{~K}$. Specimen was sintered at $1473 \mathrm{~K}$ for $1.2 \mathrm{ks}$ (a), $10.8 \mathrm{ks}$ (b), $97.2 \mathrm{ks}(\mathrm{c})$ and $291.6 \mathrm{ks}(\mathrm{d})$.

image (c). Takahashi reported that the plate-like $\mathrm{TiB}$ is a whisker. ${ }^{13)}$ Therefore, the TiB particle should be a single crystal containing few impurities and dislocations. Figure 7 represents the schematic illustrations showing the morphological change of a TiB particle at sintering temperature. The granular TiB particle before self-division (a) has an incoherent interface with the matrix and contains a large area of grain boundary because it's a fine-grained polycrystal. During sintering, the plate-like TiB particles with a coherent $\mathrm{TiB} /$ matix interface begin to grow from the initial granular $\mathrm{TiB}$ particle in the specific directions of $\beta$ matrix to expand the coherent interface (b), and then the number of the formation of plate-like TiB is gradually increased, and finally, the initial granular TiB is fully divided into a large number of plate-like TiB particles, that is, the self-division is completed.

As mentioned above, the self-division phenomenon of $\mathrm{TiB}$ particles seem to be contrary to Ostwald ripening mechanism.
However, both of the incoherent $\mathrm{TiB} /$ matrix interface and the grain boundary within $\mathrm{TiB}$ particle have high interfacial energy, while the coherent $\mathrm{TiB} /$ matrix interface has low interfacial energy. Considering these facts, we should be able to explain this phenomenon reasonably in terms of thermodynamics. To demonstrate the thermodynamic validity of the self-division, the change in total interfacial energy between before and after the self-division was estimated by using a simple model based on the experimental results. Figure 8 shows the cube approximation model on the assumption that a large cubic TiB particle, which consists of small cubic grains, is divided into $n$ pieces of small cubic TiB without changing the total volume. The sizes of initial granular TiB and grains in the TiB are $20 \mu \mathrm{m}$ and $1 \mu \mathrm{m}$, respectively. The parameters and their values needed for the estimation are listed in Table 2. It was assumed that the interfacial energy is identical between the incoherent $\mathrm{TiB} /$ matrix interface and 


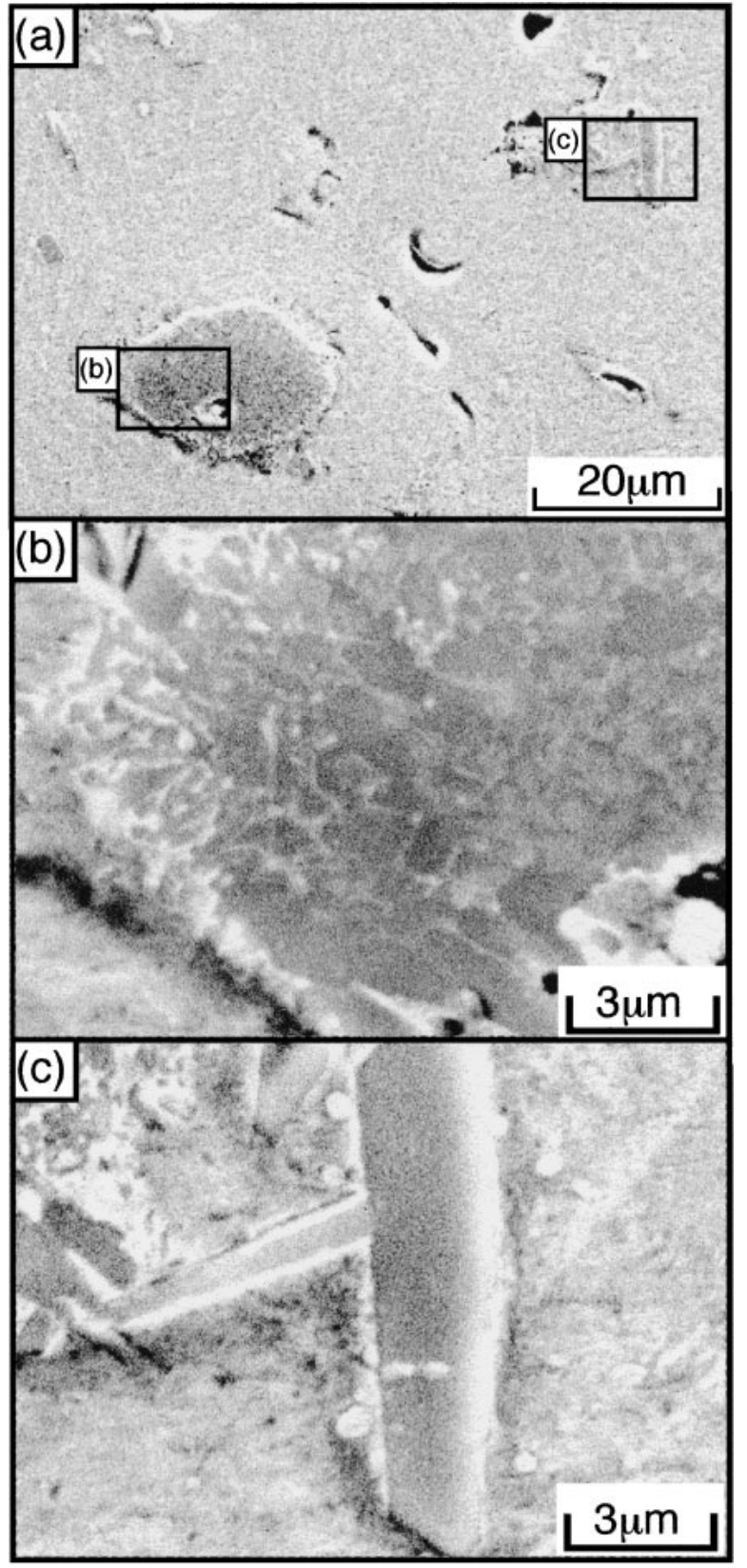

Fig. 6 SEM images of the specimen sintered at $1473 \mathrm{~K}$ for $1.2 \mathrm{ks}$. Photograph (b) and (c) are magnified microstructures of a granular TiB particle and a plate-like TiB particle in the Photograph (a), respectively. the grain boundary. The total interfacial energy before selfdivision, $E_{1}$, is

$$
E_{1}=a_{1}^{i} e_{1}^{i}+a_{1}^{g} e_{1}^{g}
$$

while that after self-division, $E_{2}$, is

$$
E_{2}=a_{2}{ }^{i} e_{2}{ }^{i}
$$

When the difference of the total interfacial energies, $\Delta E\left(=E_{2}-E_{1}\right)$, is greater than zero, the self-division is driven by the $\Delta E$. As a result of the calculation, if the $n$ value is smaller than $5 \times 10^{3}$, the self-division was found to be possible to occur. This modeling is so rough that we can not quantitatively discuss the number or size of the divided TiB, but it has been surely confirmed that the self-division is thermodynamically reasonable phenomenon. In other words, the self-division is similar phenomenon as the Ostwald ripening, in point that the interfacial energy drives the morphological change of precipitates.

\section{Conclusions}

(1) The Ti-Cr system powder compact containing $\mathrm{CrB}$ boride particles causes the chemical reaction, $\mathrm{Ti}+\mathrm{CrB} \rightarrow$ $\mathrm{TiB}+\mathrm{Cr}$, on heating to sintering temperature, and then the

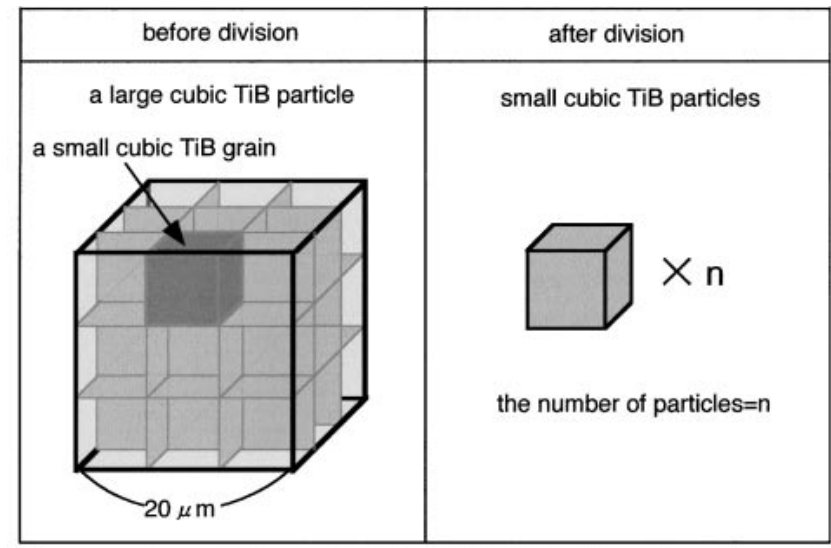

*on the assumption that ta large cubic TiB particle is divided into n pieces of small cubic TiB particles without the chagning the totall volume

Fig. 8 Schematic illustration of the cube approximation model of TiB particle before and after the self-division.

\begin{tabular}{|c|c|c|}
\hline (a) before division & (b) during division & (c) after division \\
\hline a granular TiB particle & plate-like TiB particles
\end{tabular}

Fig. 7 Schematic illustration of morphological change in a TiB particle during sintering. 
Table 2 The numerical values used for the calculation of $\Delta E$.

\begin{tabular}{lll}
\hline & before division & after division \\
\hline Area of TiB /matrix interface, $a^{i}\left(\mathrm{~m}^{2}\right)$ & $a_{1}{ }^{i}=2.4 \times 10^{-9}$ & $a_{2}{ }^{i}=2.4 \cdot n^{-2 / 3} \times 10^{-9}$ \\
\hline Area of grain boundary, $a^{g}\left(\mathrm{~m}^{2}\right)$ & $a_{1}{ }^{g}=2 \times 10^{-8}$ & - \\
\hline TiB/matrix interfacial energy, $e^{i}\left(\mathrm{~J} / \mathrm{m}^{2}\right)$ & $e_{1}{ }^{i}=1.0$ & $e_{2}=0.5$ \\
\hline Grain boundary energy, $e^{g}\left(\mathrm{~J} / \mathrm{m}^{2}\right)$ & $e_{1}{ }^{g}=1.0$ & - \\
\hline
\end{tabular}

$\mathrm{CrB}$ particles are fully replaced by the granular $\mathrm{TiB}$ particles after sintering of $1473 \mathrm{~K}-1.2 \mathrm{ks}$.

(2) When the material is held at sintering temperature, the granular TiB particle formed through the reaction is divided into many pieces of plate-like TiB particles (self-division phenomenon).

(3) The total interfacial energy including the grain boundary energy within the TiB particle is decreased through the self-division of the granular TiB particle although the $\mathrm{TiB} /$ matrix interface area is increased. The difference in the total interfacial energy corresponds to the driving force for the self-division of TiB.

\section{REFERENCES}

1) S. Abkowitz: Proc. Int. Conf. on $\mathrm{P} / \mathrm{M}$ Aerospace, Defense and Demanding Applications, F. H. Froes ed., MPIF, Princeton, NJ, 1989.

2) T. Saito and T. Furuta: Toyota Central Labs R\&D Review 29 (1994) p. 49.
3) K. Funami, M. Kobayashi and C. Ouchi: Mater. Sci. Forum 243-245 (1997) 515 .

4) K. Funami, M. Kobayashi and C. Ouchi: Tetsu-to-Hagane 85 (1999) 778 .

5) M. Hagiwara, S. Komura and Y. Kawabe: Tetsu-to-Hagane 84 (1998) 678.

6) Hwang. J.-H., T. Tagawa and H. Taira: Zairyou 47 (1998) 177.

7) T. Yoshihiro, T. Tsuchiyama and S. Takaki: J. Japan Inst. Metals 47 (2003) 362-367.

8) S. Takaki and Y. Ikeda: Proceeding of the 2nd Pacific Rim International Conference on Advanced Materials and Processing, ed. by K. S. Shin, J. K. Yoon and S. J. Kim (1995).

9) K. Okazaki, T. Tsuchiyama, N. Nakajima and S. Takaki: Mater. Sci. Forum 304-306 (1999) 121.

10) I. Barin: Thermochemical Date of Pure Subatances, VCH.

11) Y. Ikeda, S. Takaki, M. Kamata and Y. Tokunaga: Funtai-oyobiFunmatsuyakin 40 (1993) 774.

12) P. Mogilevsky, A. Werner and H. J. Dudek: Defect and Diffusion Forum 143-147 (1997) 585.

13) T. Takahashi: J. Japan Inst. Metals 59 (1995) 244-250. 